NUREG/CR-5955

ORNL/TM-12266

R1,R2,R5,R7,R8

\title{
Materials and Design \\ Bases Issues in ASME \\ Code Case N-47
}

Manuscript Completed: October 1992

Date Published: April 1993

Prepared by

R. L. Huddleston, R. W. Swindeman

Oak Ridge National Laboratory

Operated by Martin Marietta Energy Systems, Inc.

Oak Ridge National Laboratory

Oak Ridge, TN 37831-6285

\section{Prepared for}

Division of Engineering

Office for Nuclear Regulatory Research

U.S. Nuclear Regulatory Commission

Washington, DC 20555

NRC FIN 2159

Under DOE Contract No. DE-AC05-840R21400

\section{DISCLAIMER}

This report was prepared as an account of work sponsored by an agency of the United States Government. Neither the United States Government nor any agency thereof, nor any of their employees, makes any warranty, express or implied, or assumes any legal liability or responsibility for the accuracy, completeness, or usefulness of any information, apparatus, product, or process disclosed, or represents that its use would not infringe privately owned rights. Reference herein to any specific commercial product, process, or service by trade name, trademark, manufacturer, or otherwise does not necessarily constitute or imply its endorsement, recommendation, or favoring by the United States Government or any agency thereof. The views and opinions of authors expressed herein do not necessarily state or reflect those of the United States Government or any agency thereof. 


\section{DISCLAIMER}

This report was prepared as an account of work sponsored by an agency of the United States Government. Neither the United States Government nor any agency Thereof, nor any of their employees, makes any warranty, express or implied, or assumes any legal liability or responsibility for the accuracy, completeness, or usefulness of any information, apparatus, product, or process disclosed, or represents that its use would not infringe privately owned rights. Reference herein to any specific commercial product, process, or service by trade name, trademark, manufacturer, or otherwise does not necessarily constitute or imply its endorsement, recommendation, or favoring by the United States Government or any agency thereof. The views and opinions of authors expressed herein do not necessarily state or reflect those of the United States Government or any agency thereof. 


\section{DISCLAIMER}

Portions of this document may be illegible in electronic image products. Images are produced from the best available original document. 


\begin{abstract}
A preliminary evaluation of the design bases (principally ASME Code Case N-47) was conducted for design and operation of reactors at elevated temperatures where the time-dependent effects of creep, creep-fatigue, and creep ratcheting are significant. Areas where Code rules or regulatory guides may be

expected life cycles for the next-generation advanced high-temperature reactor systems, with designs to be certified by the U.S. Nuclear Regulatory Commission, have been identified as issues. Twenty-two issues were identified and brief scoping plans developed for resolving these issues.
\end{abstract} lacking or inadequate to ensure the operation over the 


\section{Contents}

Page

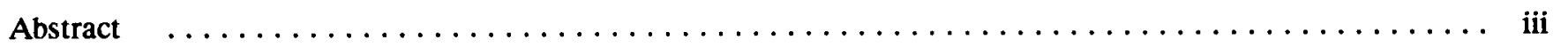

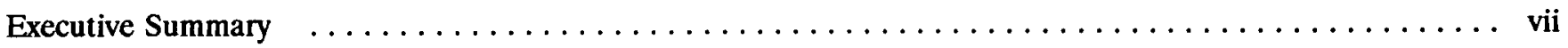

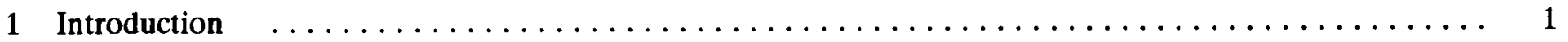

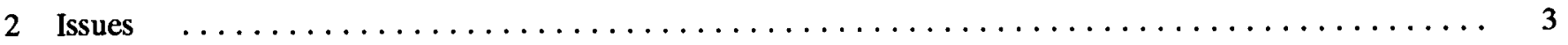

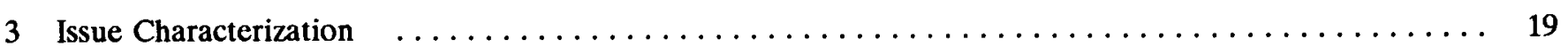

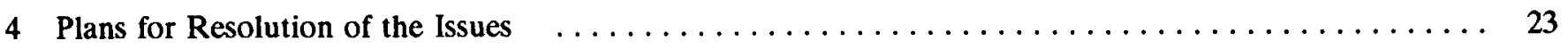

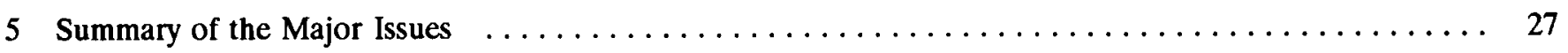

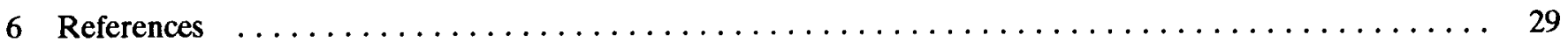

Tables

1 Summary of CCN47 allowables needing extension $\quad \ldots \ldots \ldots \ldots \ldots \ldots \ldots \ldots \ldots \ldots \ldots \ldots \ldots \ldots$

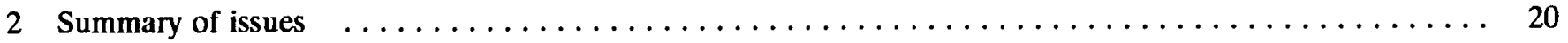

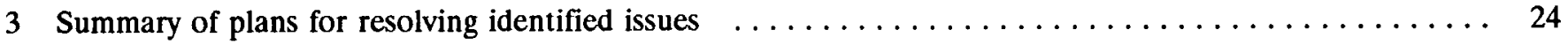

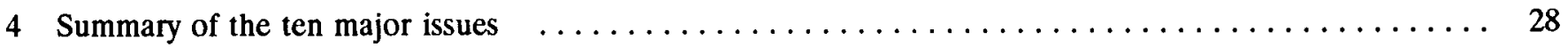




\section{Executive Summary}

The Nuclear Regulatory Commission (NRC) is working with industry to certify the designs of next-generation, advanced, power reactors that will be marketed by industry to power producing utilities within the United States and foreign countries during the next decade. This report documents results of a preliminary NRC-sponsored evaluation of the design bases (principally ASME Code Case $\mathrm{N}-47$ ) for design and operation of reactors at elevated temperatures where the time-dependent effects of creep, creep-fatigue, and creep-ratcheting are significant and must be considered in the design process.

Twenty-two issues were identified and characterized by "Type" [safety or economic], by "Bases" [(1) material and data base, (2) design bases, or (3) both], and by "Level" [six levels]. Issue "Level" was used to delineate the issues into six categories based on a number of factors depending on considerations such as plant safety, plant economics, expected cost to resolve, expected time required to resolve, whether Code rules must be modified to accommodate the next generation designs, and so on.
Brief scoping-type plans for resolving the 22 unresolved issues were developed.

A reduced list of the ten major issues was developed.

1. lack of material property allowable design data/curves for a 60 -year design life,

2. lack of understanding/validation of notch weakening effects,

3. lack of a validated weldment design methodology,

4. degradation of material properties at high temperatures due to long-term irradiation (environmental issue),

5. degradation of material properties due to long-term corrosion phenomena (environmental issue),

6. lack of validated thermal striping materials and design methodology,

7. lack of reliable creep-fatigue design rules,

8. lack of flaw assessment procedures,

9. lack of inelastic design procedures for piping, and

10. lack of rules/guidelines to account for seismic effects at elevated temperature. 


\section{Introduction}

The purpose of this report is to summarize the results of an Oak Ridge National Laboratory (ORNL) preliminary review of design bases rules for elevated temperature components of advanced reactor systems that will operate in the creep regime and to identify any issues that could negatively impact (delay) the design certification process. The study was requested and funded by the U.S. Nuclear Regulatory Commission (NRC), Office of Regulatory Research. The scope of the report addresses only issues related to ASME Code rules, particularly the rules of the hightemperature Code Case $\mathrm{N}-47$ (denoted hereafter as CCN47). ${ }^{1}$ At the direction of NRC, the report does not address design-specific issues associated with components such as transitions joints, bellows, and steam generators, because a significant amount of the detailed design information for the advanced high-temperature reactors is not yet available to support the assessments.

The NRC is working with industry to certify the designs of advanced power reactors that will be marketed by industry to power producing utilities within the United States and throughout the world in the next decade. Some of the advanced power reactors currently in the preliminary design phase, if purchased by the utilities and incorporated into the power grid, will operate at high metal temperatures where creep effects exist and which exceed the allowables in ASME Code Sects. II and III, Division 1. The creep-induced failure modes of creep-rupture, creep-fatigue, and creepratcheting must, therefore, be guarded against in the design process. Current power reactors operated by the utility industry operate at temperatures where creep effects are defined/treated by the $A S M E$ Code as insignificant (design temperatures below $800^{\circ} \mathrm{F}$ for the austenitic stainless steels and nickel base alloys and below $700^{\circ} \mathrm{F}$ for the ferritic alloys). Creep is, therefore, ignored in the design process and the rules of ASME Code Sect. III, Code of Federal Regulations (Title 10), and NRC regulatory guides form the basic design codes for these reactor systems. Section XI also provides rules for in-service inspection (ISI). For a new, higher-temperature generation of power reactors that will operate at temperatures where creep effects are significant, such as the advanced liquidmetal reactors, gas-cooled reactors, and possibly the Canadian CANDU reactors, the rules of ASME CCN47 in conjunction with the Code of Federal Regulations and NRC regulatory guides will be the dominant codes utilized for design with Sect. XI providing rules for ISI.

NRC has directed ORNL to make a preliminary review of the code design bases for the higher temperature reactor systems, which will operate in the creep regime, and to identify any code design bases issues that could negatively impact (delay) the design certification process. History has shown that modification of $A S M E$ Code rules or incorporation of new consensus rules is generally a lengthy process (i.e., 2 to 5 years or significantly more depending on the complexity of the issue) and, if required, should be initiated well in advance of projected design certification dates. Within the resources and time allocated for this study it was not possible to do an in-depth review and assessment, including appropriate references and expanded documentation, for each of the issues identified. The primary focus of this effort has, therefore, been to identify and summarize the issues. While attempting to be as objective as possible, it should be recognized that a certain level of subjectivity is involved in identifying issues. There will be differences of opinion between various technical persons. The reactor manufacturer may take a firm position that all the issues are resolved. The authors, however, feel that most persons who are technically knowledgeable in the areas identified would agree that the issues which have been identified are, in fact, issues of which NRC should be aware. A number of the issues identified are supported by recommendations developed previously from a review of breeder reactor experience by the Pressure Vessel Research Council. ${ }^{2}$ Several of the issues identified in this paper were previously identified during the Clinch River Breeder Reactor Plant (CRBRP) licensing process. $^{3}$

In general, the rules of ASME CCN47 provide the following to the designer:

1. Allowable construction materials

2. Time- and temperature-dependent allowables for a. fatigue

b. creep-rupture

3. Temperature limits

4. Service life limits (including degradation in mechanical properties due to thermal aging)

5. Design rules to guard against the following four failure modes: 


\section{Introduction}

a. ductile rupture from short-term loadings

b. creep-rupture from long-term loadings

c. creep-fatigue failure

d. gross distortion due to incremental collapse and ratcheting

6. Brief rules are provided to guard against failure due to

a. loss of function due to excessive deformation

b. buckling due to short-term loadings

c. creep buckling due to long-term loadings

Results of the ORNL review are summarized in the balance of this report. Section 2 summarizes the issues that have been identified with a brief description of each issue. Section 3 , then, summarizes the issues and categorizes them by "Type," "Bases", and "Level." Issue "Type" is used to denote whether the issue is a safety or an economic issue. Issue "Bases" is used to indicate whether the issue is predominantly a material/data base issue, a design bases issue, or both. Issue "Level" is used to further delineate the issues into six categories based on a number of factors depending on considerations of plant safety, plant economics, expected cost to resolve the issue, expected calendar time required to resolve the issue, whether Code rules must be extended if they are to be used as the design bases for future 60-year high-temperature plants, etc.. An issue designated as a safety issue is one that would place the public at risk if not resolved. An issue designated as an economic/cost issue is one that would add excess conservatism and cost to the nuclear power plant if not resolved, but would not place the public at significantly greater risk if not resolved. Section 4 provides preliminary scoping-type plans for resolution of the issues, and Sect. 5 identifies what are considered the ten major issues. 


\section{Issues}

Twenty-three issues have been identified. Twenty-two of the issues are unresolved. Some are obviously more important than others. At the end of each issue description, each issue is categorized as (1) a "material and data base issue," (2) a "design bases issue," or (3) both. The issues are summarized beginning with "material and data base issues," followed by issues which are both "material and data base" and "design bases" issues, and finally by "design bases" issues. The issues are not listed in any priority order.

\section{Issue 1: Lack of Material Property Allowable Design Data/Curves for 60-Year Design Life}

Material property design allowables and curves in CCN47 currently limit design life to $300,000 \mathrm{~h}$ (34 years), whereas the advanced reactor systems in the next decade will likely be designed for lives of 60 years. It will be necessary, therefore, to extend the current Code allowables to at least a 525,000-h (60-year) design life. Data allowables/curves needing extension are identified in Table 1.

This issue is categorized as a material and data base safety issue.
Issue 2: Degradation of Material Properties at High
Temperatures due to Long-Term Irradiation

The effects of long-term (60-year) irradiation on material properties and failure at temperatures in the creep range are complicated by the interaction of irradiation-induced transmutation products and thermal processes such as precipitation. The results of high-temperature irradiation depend on both temperature and irradiation exposure as well as the rate at which the resulting processes progress. There are no specific design rules in the ASME Code to cover this important area. It is left to the reactor manufacturer designers to devise a method to estimate the degree of degradation and to defend it to the NRC. There are insufficient data for the broad range of temperatures and fluences required for the design of high-temperature reactor systems. However, the mechanisms of high-temperature irradiation embrittlement are known, and sufficient data are available for several materials to provide guidance to establish a testing program to acquire the necessary data.

The primary cause of high-temperature irradiation embrittlement in alloys is the production of helium and its subsequent migration to grain boundaries. The

Table 1. Summary of CCN47 allowables needing extension

$\begin{array}{lll}\text { 1. } \mathrm{S}_{\mathrm{t}} & \text { Tables I-14.4 } & \text { Figures I-14.4 } \\ \text { 2. } \mathrm{S}_{\mathrm{mt}} & \text { Tables I-14.3 } & \text { Figures I-14.3 } \\ \text { 3. Expected Minimum } & \text { Tables I-14.6 } & \text { Figures I-14.6 } \\ \text { Stress-To-Rupture } & & \\ \text { 4. Thermal Aging and Weld } & \text { Tables I-14.10 } & \\ \text { Strength Reduction Factors } & & \text { Figures I-14.13 } \\ \text { 5. } \mathrm{S}_{\mathrm{mt}} \text { (bolting) } & \text { Tables I-14.13 } & \text { Figures T-1420-1 } \\ \text { 6. Design Fatigue Strain Range } & \text { Tables T-1420-1 } & \end{array}$

[extension will be needed if any cycle requiring creep-fatigue analysis for design certification is $<31.56 \mathrm{~min}$ in duration for $304 \mathrm{SS}, 316 \mathrm{SS}, 800 \mathrm{H}$ or is $<36.82 \mathrm{~min}$ for $2.25 \mathrm{Cr}-1$ Mo steel (i.e., 60 years $/ 10^{6}$ cycles $=31.56 \mathrm{~min}$ for 304 SS, etc.)]

7. Average Isochronous Stress-Strain Curves

Figures T-1800 
two most common sources of helium are transmutation of boron and transmutation of nickel, both by thermal neutrons; $1 \mathrm{wt} \%$ of boron will eventually result in 1 at. \% helium. At a thermal fluence of $5 \times 10^{19}, 10 \%$ of the boron is converted to helium. By a thermal fluence of $10^{21}, 90 \%$ of the boron is converted. Production of helium from nickel transmutation is complicated by the formation of an intermediate nuclide. As an approximation, a thermal fluence of $10^{21}$ produces about 1 appm (1 atomic part per million) helium in an austenitic stainless steel. The production of helium from boron and nickel are, then, roughly equal at a thermal fluence of $10^{21}$ after which nickel rapidly dominates as the source of helium.

Helium embrittlement depends on temperature, concentration of helium at grain boundaries, and rate of deformation. Helium embrittlement has not been observed in austenitic stainless steels at temperatures below $450^{\circ} \mathrm{C}\left(842^{\circ} \mathrm{F}\right) .^{4}$ At temperatures of $550^{\circ} \mathrm{C}$ $\left(1022^{\circ} \mathrm{F}\right)$, however, ductilities well below $1 \%$ have been observed for long-term creep tests. ${ }^{5}$ Van der Schaaf et al. have shown helium embrittlement at very low levels of helium in AISI Type 304 stainless steel in creep tests. ${ }^{6.7}$ Following sequential creep and fatigue tests, they conclude that the effect of irradiation is on creep resulting from high-temperature helium embrittlement. Fatigue tests of Type 316 stainless steel irradiated in a mixed-spectrum reactor producing several hundred appm helium showed minimal effect of irradiation at $550^{\circ} \mathrm{C}\left(1022^{\circ} \mathrm{F}\right)$ but showed a reduction of life at $650^{\circ} \mathrm{C}\left(1202^{\circ} \mathrm{F}\right)$, attributed to creep damage during the tension portion of the fatigue cycle. ${ }^{8}$ Tensile tests also show impaired but measurable ductility, even with several thousand appm helium, provided that the temperature is not above $500^{\circ} \mathrm{C}\left(932^{\circ} \mathrm{F}\right) .^{9}$ If the strain rate were on the order of that of a creep test, however, severe embrittlement would be expected.

Van der Schaaf et al. conclude that the current creepfatigue design method is probably conservative for AISI type 304 stainless steel in the irradiated condition. $^{6}$ There are, however, insufficient data to draw this conclusion for $\mathrm{CCN} 47$ materials in general and particularly for the fluences and temperatures associated with future advanced high-temperature reactors such as the advanced liquid-metal reactor (ALMR) and modular high-temperature reactor (MHTGR).

This issue is categorized as a "material and data base safety issue."
Issue 3: Degradation of Material Properties due to Long-Term Thermal Aging

The long-term (60-year) effects of thermal aging on material properties and failure at temperatures in the creep range are poorly understood. Experiences in the fossil power industry provide many examples of cracking and failures in low-alloy steels and stainless steels that result from degradation during long-time exposures in the temperature range 316 to $538^{\circ} \mathrm{C}(600$ to $1000^{\circ} \mathrm{F}$ ).

In regard to austenitic stainless steels, some embrittlement is attributed to the precipitation of sigma phase, Laves phase, alpha prime, or the G-phase from delta ferrite. These types of embrittlement have been of concern in castings, welds, and duplex alloys. The Materials Properties Council ${ }^{10}$ and the Pressure Vessel Research Council have been evaluating the significance in regard to its importance in the nuclear industry; hence the issue is being addressed to some extent. In future construction, it appears that close composition specifications will be required to mitigate the rate at which the materials embrittle.

Ductility losses due to the formation of carbides in austenitic alloys has been another concern. First, carbides may precipitate as sheets on the grain boundaries of stainless steels and similar alloys and reduce overall ductility. This phenomenon has been of considerable concern in regard to the influence of cold work in combination with carbide precipitation. The ductility of Types 304 and 316 stainless steels and Alloy $800 \mathrm{H}$ have diminished to $1 \%$ for some combinations of cold work, temperature, and stress. Second, the loss of carbon to the precipitates may destabilize austenite and promote the development of ferrite or thermal martensite when the material is cooled to low temperatures. The formation of weak phases on grain boundaries may produce reduced strength and low ductility failures at high temperatures. Experience with this type failure has been found in Type 304 stainless steel. As a result, a supplemental creepfatigue test is currently being considered by Sect. III of the $A S M E$ Code as part of a purchase specification for critical components.

Degrading of bainitic and martensitic steels may occur from a number of thermal aging phenomena. The "885 embrittlement" is well known, and warnings are provided in the ASME Code. However, long-time exposure of materials such as Grade 91 steel introduces a coarsening of the microstructure and the precipitation of Laves phase. The yield, ultimate, and 
creep strength decrease. Materials that are tempered or postweld heat treated to near minimum tensile strength could undergo further loss of strength. ${ }^{11}$ The problem seems to be more severe for service above $566^{\circ} \mathrm{C}\left(1050^{\circ} \mathrm{F}\right)$, but only a few heats of material have been examined.

Tables of allowable stress "knock down" factors to account for degradation due to thermal aging are currently in the approval process within the $A S M E$ Code Sect. III Subcommittee. The aging data on which these factors are based need to be from sufficiently long-term tests to permit safe extrapolation to the expected 60-year life of future nuclear reactor plants.

This issue is categorized as a "material and data base safety issue."

\section{Issue 4: Degradation of Material Properties due to Corrosion Phenomena}

This issue focuses on the lack of understanding of potential long-term degradation of material properties due to corrosion phenomena. The ASME Code does not explicitly consider corrosion effects in the rules for new construction. The burden is on the designer to select the proper material for the application and to introduce corrosion allowances when needed. However, the high-temperature design code case for ASME Sect. III (CCN47) is somewhat limited in the materials that have been covered. General corrosion, mass transport due to temperature or compositional gradients (such as might occur in an ALMR system), stresscorrosion, corrosion-fatigue, radiation-assisted stresscorrosion cracking, and crevice-corrosion are some of the many degradation mechanisms associated with corrosion. The materials in $\mathrm{CCN} 47$ may be susceptible to any or all of these corrosion mechanisms, but the problem must be addressed on a case-by-case basis.

One issue of considerable interest concerns the role of corrosion in creep-fatigue damage accumulation. In the $\mathrm{H}$ grades of stainless steels, as well as in Alloy $800 \mathrm{H}$, carbides form on grain boundaries. These carbides consume chromium and have poor oxidation resistance. Under creep-fatigue loadings the oxidation enhances the grain boundary crack propagation rate under cyclic loading. Because the character of the grain boundary precipitate depends on chemistry and thermal-mechanical processing, as well as exposure conditions, the tendency for degradation varies significantly. The damage mechanism needs further study.

In regard to ferritic steels such as SA533, Grade 22, and Grade 91, the nature of the corrosion-related creep-fatigue damage in oxidizing environments appears to be the formation of oxide spikes that progress inward from the surface. ${ }^{12}$ Attempts to model this corrosionrelated mechanism in terms of a creep-fatigue interaction have not been successful. Creep-fatigue of SA533 steel under corrosion conditions has just recently been covered by the $A S M E$ Code in Code Case N-499 (Ref. 13) for the MHTGR program.

The importance of environment in the creep and fatigue crack propagation mechanisms is well established. Again, it remains an issue that can only be addressed when specific reactor operating conditions are known.

This issue is categorized as a "material and data base safety issue."

\section{Issue 5: Lack of Property Allowables Based on Cur-} rent Melting and Fabrication Practices

The high-temperature nuclear codes were developed in the 1970s. The steels that were evaluated in collecting the data base for Types 304 and 316 stainless steel were produced by air melting practice. The argon/oxygen decaraburized (AOD) process is now used in the United States. The difference in behavior is not expected to be large, but little or no information is available for comparison of data for newly melted heats with historic data.

Although the Japanese continue to have interest in $H$ grades of unstabilized stainless steels, there has been a shift in France, Germany, and Japan to the use of low-carbon, high-nitrogen steels for hightemperature applications. ${ }^{14}$ This selection reduces concerns regarding sensitization and corrosion and long-time embrittlement. Modifications of Alloy 800 are also being considered. These steels are not included in ASME CCN47.

There are issues in regard to ferritic alloys, as well. For example, catastrophic failures have occurred in fossil power plants. Reheat steam line piping has failed in at least two plants in the United States after long-time service. These were low-alloy steels. Carbon 
steel hot-formed piping has failed in Spain. Coldformed pipe bend failures have occurred in the United States. A feedwater line in a power plant in Greece failed due to creep embrittlement. The reasons for unexpected failures in structural steels have not been established. The Materials Properties Council is working toward developing an understanding and solution, but at this point there is nothing to preclude such failures in nuclear plants.

The ferritic steel Grade 91 has not been produced in the United States in many years. The creep rupture data base for this steel, however, has been greatly expanded since Code approval in the early 1980s. European and some Japanese heavy-section products have been found to be weaker than expected. ${ }^{15}$ Reasons for lower strength have not been fully established, but lowering of the stress allowables is being considered.

Reactor manufacturers tend to order special chemistries within a grade, and all of the consequences are not recognized. For example, the use of vacuummelted, electroslag-remelted Grade 22 steel for breeder reactor applications produced a material of exceptionally low strength. ${ }^{16}$

The hot extrusion process has been known to produce cavitation on grain boundaries of Type 304 stainless steel that lead to low creep ductilities. ${ }^{17}$

Welding consummables and procedures continue to be a problem, In particular, the strength of weldments in Grade 91 steel is a major issue that is not fully resolved. Weld strength reduction factors have been developed for CCN47. Even so, failures in Grade 91 pipe welds have occurred due to improper postweld heat treating.

This issue is categorized as a "material and data base safety issue."

\section{Issue 6: Degradation Effect of Small Cyclic Stresses}

Bainitic and martensitlc steels owe their strength to the development of a precipitate-stabilized fine dislocation microstructure. Under large cyclic strains, it is well known that these materials undergo strain softening. However, very small cyclic strains, when superimposed on primary stresses, appear to accelerate the rate at which the microstructure coarsens. Depending on the strength level, it is not unusual to decrease the creep rupture life by 1 to 2 orders of magnitude. ${ }^{18}$ Although full reversals in stress for through thickness are rare, the severe degradation in strength is of concern and should be examined in more detail for the bainitic and martensitic steels.

This issue is categorized as a "material and data base safety issue."

\section{Issue 7: Creep-Induced Failures at Temperatures Below CCN47 Limits}

Creep-induced failures in ferritic steel piping have occurred in fossil power stations at temperatures below where creep effects are defined as significant by CCN47 [i.e., $\mathrm{CCN} 47$ sets $371^{\circ} \mathrm{C}\left(700^{\circ} \mathrm{F}\right)$ for ferritic steels as the temperature above which creep effects must be considered]. If these failures are indicating that similar failures are possible in nuclear reactors designed for $343^{\circ} \mathrm{C}\left(650^{\circ} \mathrm{F}\right)$ operation, particularly for future systems with a 60-year operating life, then it may be necessary to account for creep effects at temperatures in the 316 to $371^{\circ} \mathrm{C}\left(600\right.$ to $\left.700^{\circ} \mathrm{F}\right)$ range.

This issue is categorized as both a "material and data

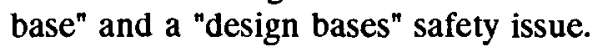

\section{Issue 8: Use of Average vs Minimum Material Properties in Design}

Use of average vs minimum material properties for design analyses continues to be an issue. This issue was discussed at some length in the previously referenced Pressure Vessel Research Council study. ${ }^{2}$ Quoting from this study:

The prediction of inelastic structural behavior depends strongly upon the material properties employed in inelastic analysis. In general, strain accumulation and fatigue damage increase with a decrease in the yield strength of the material, whereas creep damage increases with an increase in yield strength. Therefore, an appropriate selection of a set of material properties for structural analysis is not obvious. For example, when design limits are marginally satisfied, it may be necessary to bound analytical predictions by at least two analyses with average and minimum material property assumptions. 
Current LMFBR structural design guidance does not help to resolve the confusion regarding property selection. From various ASME Code committee deliberations over the last two decades, a consensus has emerged on the use of average material properties for detailed inelastic analysis. Code Case N-47 contains minimum yield strength values, but average creep properties are embedded in the average isochronous stress-strain curves. Furthermore, it is not clear how minimum isochronous curves for ratcheting and buckling calculations may be obtained from the average curves presented in CCN47. Traditionally, the ASME Code has defined average yield strength as 1.25 times the minimum value, but the legitimacy of this factor, and/or its use in the context of the isochronous curves, is not obvious for elevated temperature design.

The use of average material properties for detailed inelastic analysis is recommended in NE Standard F9-5T, ${ }^{19}$ because it is representative of the many different heats of materials manufactured, and because the creepfatigue damage based on average properties is typically higher than the damage based upon minimum properties. Although a predicted strain accumulation based upon average properties would be lower than that predicted using minimum properties, it is of secondary importance, because the strain limits are not associated with a failure mode.

In practice, it is not possible to determine, a priori, the worst case combination of minimum and/or maximum strength and deformation properties for each loading condition, nor would such a minimum/maximum combination be physically consistent with actual material behavior. A probabilistic study has been conducted by ORNL to evaluate, from the assumed average properties of different heats of material, the effect of the observed material variability. The results indicate that the ASME Code design margins for strain accumulation are exceeded in about 50 percent of the material property combinations (designated as heats of material) used in that study. Code design margins for creep damage were exceeded in 1.8 percent of the 'heats'; fatigue damage limits were never violated. Experimental data indicate that significant structural life remains after the initial cracking prediction based upon the Code Case $\mathrm{N}-47$ creep-fatigue damage calculation, thus, exceeding the ASME Code design limit (based upon crack initiation) does not mean structural failure. Even violation of the creep damage limits (which only occurred for $1.8 \%$ of the 'heats') does not necessarily mean that structural failure will occur.

Ambiguities regarding the use of minimum and average material properties should be clarified. A simple, final recommendation could be based upon elevated temperature fossil-fired plant experience, long-term LMFBR structural test data, probabilistic studies of material property selections consistent with field data instead of random material properties from as-received materials and as-built structures, and analytical predictions based upon reasonable material property variations. ${ }^{2}$

This issue is categorized as both a "material and data

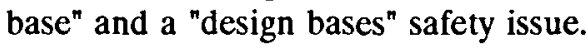

\section{Issue 9: Lack of a Design Methodology for Modified 9 Cr-1 Mo Stcel}

The number of materials options in $\mathrm{CCN} 47$ for designer use is very limited. New materials have been developed that could provide additional options to the designer. The addition of modified $9 \mathrm{Cr}-1$ Mo steel to Sect. III and to the elevated-temperature Code cases would significantly benefit the U.S. liquid-metal reactor (LMR) designer (i.e., modified $9 \mathrm{Cr}-1$ Mo steel has been added to ASME Code Case $\mathrm{N}-253^{20}$ but not to $\mathrm{CCN} 47$ ). Should designers choose to use modified $9 \mathrm{Cr}-1 \mathrm{Mo}$ steel in next-generation designs, then appropriate design allowable properties and design rules would have to be added to the existing Code. Efforts have been in progress for the past few years to add modified $9 \mathrm{Cr}-1$ Mo as a Code material; however, this activity has not addressed new design methods that would be needed for this type of material, which undergoes cyclic strain softening as well as creep softening. Modified $9 \mathrm{Cr}-1 \mathrm{Mo}$ steel is a ferritic/ martensitic steel that is being pursued by the U.S. LMR program as an attractive alternative to the austenitic stainless steels and to $2.25 \mathrm{Cr}-1$ Mo steel. It has, at temperatures up to $593^{\circ} \mathrm{C}\left(1100^{\circ} \mathrm{F}\right)$, stress 
allowables equivalent to 304 stainless steel; it is twice as strong (short time and creep) as $2.25 \mathrm{Cr}-1$ Mo steel above $482^{\circ} \mathrm{C}\left(900^{\circ} \mathrm{F}\right)$; it appears to be as resistant to thermal striping as Inconel 718; it is resistant to chloride and caustic stress corrosion; perhaps most importantly, it has thermophysical properties leading to reduced thermal loadings. However, it has inelastic behavioral features that are substantially different from those of the other Code alloys that have been considered, and these attributes are much more difficult to model; the existing constitutive equation framework for inelastic design analyses, as well as the basis for simplified analyses, will thus require significant modification, and several of the basic premises on which Code rules and criteria are based will require reevaluation for modified $9 \mathrm{Cr}-1$ Mo steel. Likewise, early indications are that its time-dependent failure behavior is different from that of the stainless steels. Thus, a high-temperature structural design technology effort is needed to develop material behavior models, failure criteria, and simplified methods, and also to conduct confirmatory structural tests as needed to validate the overall design methodology. At very high temperatures Alloy 617 has properties that are similar to those of modified $9 \mathrm{Cr}-1$ Mo steel. Like modified $9 \mathrm{Cr}-1 \mathrm{Mo}$, Alloy 617 properties are very rate dependent; thus, one has difficulty distinguishing between rate-dependent creep and plasticity. A Code case was developed previously for 617 and is currently being considered by the Code Subcommittee on Design. This Code case might also provide a framework for modified $9 \mathrm{Cr}-1 \mathrm{Mo}$.

This issue is categorized as both a "material and data base $^{n}$ and a "design bases" safety issue.

\section{Issue 10: Lack of Understanding/Validation of Effects of Short-Term Overload Events on Sub- sequent Mechanical Properties}

Based on early data collected for the Fast Flux Test Facility (FFTF) at Hanford, Code Subgroups (SGs) concluded that significant degradation of mechanical properties as a result of short-term overload events was not a significant problem; however, more recent information suggests that this is still an issue.

The "negligible creep curve" in the ASME Code (N-47 and N-253) is less conservative than the French Code RCC-MR. In view of the long-life design for nuclear plants, there is a need to reconsider the temperature threshold for creep damage as well as methods to calculate damage introduced by over-excursions of either stress or temperature. Stress excursions that produce plasticity could harden the matrix and produce residual stresses. At lower temperatures relaxation rates are low, and residual stresses may be retained at very high levels. High residual stresses promote cavity growth and creep damage. The isochronous stress vs strain curves in $\mathrm{CCN} 47$ are not good indicators of the relaxation strength of the materials because they do not include strain aging effects that occur at temperatures around $538^{\circ} \mathrm{C}$ $\left(1000^{\circ} \mathrm{F}\right)$ and lower. High residual stress can be retained for very long times, ${ }^{21}$ and cavities can be nucleated at very low strain levels in stainless steels. Few data are available to provide information on the effects of thermal cycling over long times. Small overtemperature excursions and combined stress/ temperature cycling are known to degrade the strength of some steels, and the experience in the fossil power industry suggests that this is a continuing problem. Quantification of history effects, other than by simple linear damage concepts, has been difficult. Lack of reliable data has been a problem.

This issue is categorized as a "material and data base safety issue."

\section{Issue 11: Lack of Validated Thermal Striping Materials and Design Methodology}

Rapid mixing of liquid-metal coolant streams as they exit the reactor core at different temperatures in a LMR system results in rapid thermal fluctuations that, unless sufficiently mitigated by design or material thermal resistance, are transmitted to the upper internal structure of the reactor. Structural components will experience an estimated $10^{6}$ to $10^{10}$ thermal (strain-controlled) cycles during the 60-year life of a plant. Thermal fatigue (denoted as thermal striping) induced failure of components will occur with life depending on the material selected and the magnitude and frequency of the thermal fluctuations. The thermal fluctuations in reactors such as the sodiumcooled LMR are, in general, of sufficient magnitude to result in long-term cracking and failure of components. This phenomenon results in three interrelated issues:

1. What is the appropriate material to utilize for components undergoing severe thermal striping? General Electric (GE) tends to use Inconel 718 in critical regions since it was used in the CRBRP 
design.2 Their designs incorporate 316 stainless steel (SS) in the less critical regions. Conversely, Westinghouse researchers have gone on record in a published paper $^{23}$ stating that 718 thermal striping resistance (or lack thereof) raises questions as to the material's suitability for permanent reactor components operating in a sodium environment under thermal striping conditions. Alloys such as modified $9 \mathrm{Cr}-1$ Mo steel are also candidate materials for thermal striping applications.

2. Except for stress allowables for bolting, there are no design allowables and design criteria in $\mathrm{CCN} 47$ for Inconel 718. CRBRP criteria were developed prior to the availability of thermal striping data, which fall at the lower bound of high-cycle fatigue data, and, therefore, raises concern as to whether the currently used design procedures and margins are sufficiently conservative to cover the range of material and design uncertainties associated with long-life components for future high-temperature reactor plants. ${ }^{23}$ In addition, the CRBRP engineering staff recognized the need for a knock-down factor for grain size. To the knowledge of the authors, there appears to be no concensus on whether this factor is needed or will be used. GE apparently has not used the factor.

3. Assuming that cracking will occur, then the crack growth methodology for demonstrating a cracktolerant design at temperatures where creep effects are significant is not included in existing Code rules and needs to be developed. Thermal striping test programs have produced 22 data points for 316 SS, 11 for Inconel 718, and 12 for modified 9 Cr-1 Mo steel. Both Rockwell ${ }^{24}$ and Westinghouse ${ }^{23}$ have developed design guid-ance for $316 \mathrm{SS}$, but the recommendations were different. Neither could develop guidance for 718 . Their experimental data for modified $9 \mathrm{Cr}-1 \mathrm{Mo}$ did not agree with respect to the resistance of modified $9 \mathrm{Cr}-1 \mathrm{Mo}$ relative to that of 718 . The GE ALMR technology plan for thermal striping ${ }^{2}$ addresses only modified $9 \mathrm{Cr}-1 \mathrm{Mo}$ steel, which they apparently are not planning to use in the ALMR.

The previously referenced Pressure Vessel Research Council study ${ }^{2}$ identified thermal striping as a major issue for the high-temperature LMRs. The following four paragraphs are quoted from that study.
Thermal striping is a high-cycle fatigue problem which is not specifically addressed in the ASME Code. Accurate assessment of thermal striping fatigue damage requires definition of: (a) the hot and cold fluid temperature history, (b) evaluations of the boundary layer effect, (c) mixed fluid temperature, (d) metal surface temperature, and the high-cycle, strain-controlled, fatigue curve for the material.

Thermal striping is not a new failure mode; hence, it does not require development of special analysis methods, but may need an additional design criterion which is separate from the general, creep-fatigue damage evaluation procedure in Code Case N-47. Thermal resistance depends upon inherent material fatigue strength, component surface finish, and other possible environmental factors present during plant operation. Need for additional thermal striping testing also coincides with a need to extend the current ASME Code fatigue design curves beyond $10^{6}$ cycles to establish an endurance limit for strain-cycled thermal loadings.

Thermal striping tests have been performed on cylindrical specimens of Type 316 stainless steel, Alloy 718, and modified $9 \mathrm{Cr}-1$ Mo steel. The experimental results indicate that the thermal striping fatigue endurance for Type 316 stainless steel is equal to, or better than, the endurance limit obtained from uniaxial fatigue data. On the other hand, Alloy 718 material thermal striping fatigue endurance is sensitive to initial flaw size and surface finish, and depends upon product form. The thermal striping performance of modified $9 \mathrm{Cr}-1 \mathrm{Mo}$ steel is superior to both the Alloy 718 and Type 316 stainless steel materials. On the other hand, thermal striping tests on rectangular bars indicate that: (a) the modified $9 \mathrm{Cr}-1$ Mo steel performance is about the same as that observed for Alloy 718, and (b) the endurance limit for LMFBR materials cannot be established even after $2 \times 10^{6}$ cycles. Extension of the ASME Code fatigue curves into the high-cycle regime will ultimately be necessary for resolution of the thermal striping issue. Procedures for characterizing the actual fluid and metal temperatures under realistic mixing 
conditions are also needed. Past experience suggests that, for the same hot and cold fluid stream temperature history, the thermal fluctuations measured on the surface of the cylindrical specimen in a thermal striping test facility are more severe than those estimated in the actual operation of EBR-II and FFTF.

This issue is categorized as both a "material and data base" and a "design bases" issue.

\section{Issue 12: Lack of Reliable Creep-Fatigue Design Rules}

Rules for design against creep-fatigue failures are located in CCN47, Appendix T (T-1400 for base metal and T-1700 for weldments). One has the choice of using elastic rules (typically denoted as simplified rules) or inelastic analyses rules, which are more timeconsuming to use and costly to apply. In both cases, creep-fatigue damage is based on a linear summation of time and cycle fraction damage with the total accumulated damage over the component lifetime limited by the "creep-fatigue damage envelope" or "D Diagram."

The simplified rules have been criticized as being "empirical, excessively conservative, and difficult to understand and apply in the design process."2 Perhaps the greatest concern by the Code SGs, however, is the lack of conservatism demonstrated by the inelastic rules in thermal transient tests and in the Eddystone Plant pipe failures. Need for improved elastic creepfatigue rules has been under study/review by the ASME Code SGs for some time now. New/improved rules were incorporated into $\mathrm{CCN} 47$ during 1990 and were intended to be more accurate, easier to understand, and easier to apply; however, the inelastic rules are still based on the same methodology (linear time and cycle fraction damage), which, as previously noted, has been shown to utilize an excessive amount of the Code safety margin in the case of the Eddystone Plant pipe failures and also in laboratory thermal transient tests. As a result of this concern, the ASME Code SG on Elevated Temperature Design (which is a SG of Subcommittee on Design) increased the safety margin to better accommodate these uncertainties.

There are also differences of opinion relative to use of isothermal data for predicting transient events (i.e., current Code rules are based on isothermal data, whereas the actual transient events occur over a temperature range).

The current inelastic rules have been shown to predict conservative lives (within CCN47 margins) for shorttime laboratory tests conducted mostly under tensile and/or compressive hold time cycles that are repeated until specimen failure. But, it has also been demonstrated that by interspersing blocks of high-cycle fatigue (HCF) with the slower creep-fatigue (hold time) cycles, CCN47 safety margins can be significantly eroded. ${ }^{26}$ There is concern that the margins could potentially be exceeded. The general explanation has been that only a few of the creep-fatigue cycles early in life may initiate a crack that propagates rapidly during the HCF cycles, thus resulting in earlier failures than would normally occur under pure HCF cycling. Relative to life under creep-fatigue cycling, some researchers postulate the existence of a saturation effect with hold time such that damage would not continue to grow and/or accelerate at long hold times. Others suggest a restoration of fatigue resistance for very long hold times. In fact, there are no long-term data, and no one can state with confidence what will happen in the long term. Most laboratory tests are typically conducted with hold times of $<30 \mathrm{~min}$ (with a few tests with hold times as long as $10 \mathrm{~h}$ ), whereas reactor hold periods range up to $\sim 1500 \mathrm{~h}$ (LMR). There is no clear consensus regarding a replacement for the linear damage model now used in CCN47. An improved, more reliable model, however, needs to be developed, validated, and integrated into the design process.

This issue is categorized as both a "material and data base" and a "design bases" safety issue.

\section{Issue 13: Difficult, Overly Conservative Ratcheting Design Rules}

Rules for design against ratcheting failures are located in CCN47, Appendix T (T-1200 and T-1300). Ratcheting rules are designed to limit the accumulated inelastic strain over the lifetime of the component. To ensure that accumulated deformation does not exceed Code allowables, one has the choice of "elastic or simplified inelastic" rules (typically referred to as the simplified rules) or detailed "inelastic analyses, " which are significantly more time-consuming and costly to apply. The existing Code rules have been criticized as being overly conservative as well as being difficult to understand and apply. 
This issue was previously identified by the Pressure Vessel Research Council in Ref. 2. Quoting from their findings:

....ratcheting rules, based upon 'elastic' structural analysis, are somewhat empirical and arbitrary, excessively conservative, and sometimes confusing to follow. Conservatism has crept into the rules to achieve consensus opinion. Additionally, the current rules cannot be applied to structural discontinuities. It has been shown in Refs... that ratcheting Test No. 3 in the 1983 version of Code Case N-47 (Test Number B-1 of N-47-T-1332 in the 1987 version) would not be appropriate for doublesided thermal shocks. Confusion is also created by frequent use of the statement 'unless otherwise justified, any stress with elastic follow up... should be included (considered) as primary stress...'

Since termination of the CRBRP project and since the Pressure Vessel Research Council issued its findings, CCN47 rules for design against ratcheting failure were modified/improved (December 1990) by ASME to make them generally applicable (i.e., the previous rules were not applicable to nonaxisymmetric geometries and to components with nonlinear temperature gradients). Unlike the previous rules, the new rules have been formulated to permit their application to areas of structural discontinuity. In addition, treatment of stresses with elastic follow-up has been a design issue. This has now been better clearified in the Code rules [CCN47, Appendix T, 1331(d)]. Since termination of the CRBRP Project, ASME has modified these rules to classify all secondary stresses with elastic follow-up as a primary stress, which cleared up some of the Code vagueness.

ORNL's overall assessment is that (1) the issue is primarily an economic issue as opposed to a safety issue, which would place the public at risk; (2) the rules apparently incorporate excessive conservatism, which increases the cost of nuclear plants; and (3) improvements to the rules are needed from a design methodology viewpoint.

This issue is categorized as a "design bases economic issue."

\section{Issue 14: Lack of a Validated Weldment Design Methodology}

There is almost universal recognition of the lack of weldment-specific design criteria as a significant technology problem for high-temperature reactors and particularly for the ALMR. There are a significant number of factors that control weldment creep and fatigue strength. There is a general lack of understanding as to which factors are of primary importance and, therefore, should be the ones included in an overall weldment design methodology. Some 11 weldment failures occurred in the French Phenix reactor during the early period of startup and operation. ${ }^{27}$ In the CRBRP licensing process NRC identified the threat of early weldment cracking, particularly in components subjected to repeated thermal transient loadings, as the number one unresolved structural issue (Finding No. 1). ${ }^{3}$ Quoting (Finding No. 1),

potential cracking problems in weldments of the materials of interest operating at the elevated temperatures of interest are a cause for concern. A number of important factors apparently have not been included in the CRBR application for weldments in service at elevated temperatures. The structural integrity of weldments in service at elevated temperatures has not yet been satisfactorily demonstrated by the applicants. The following additional factors must be taken into account by the applicants:

- consideration of crack initiation in the heataffected zone (HAZ) of the weldment exposed to cyclic sodium temperatures at the inside surface;

- consideration of the creep-fatigue and creep-rupture damage peculiar to the material property variations or metallurgical notch effects at weldment

- consideration of time rate, cyclic rate, and hold-time effects on the HAZ of the weldment in the presence of long shallow cracks;

- consideration of the enhanced creep in the remaining uncracked wall thickness caused by residual stresses and thermal cycling; and

- evaluation of stability of remaining uncracked wall ligament for operation in the creep regime. 
A 5-year confirmatory program of tests and analyses was indicated by NRC as being required to provide quantitative evaluation of the above open questions for the parameters of interest in the CRBRP.

As a result of NRC's concern, the national laboratories and ASME Code SGs have done some work toward development and validation of a design methodology. Stress-rupture design factors for weldments for load-controlled stresses have been developed and incorporated into CCN47 (Ref: Section 3221 and Tables I-14.10) for establishing the $S_{t}$ and $S_{m t}$ allowable stress intensities. Some activity has continued on development of similar factors for design of weldments against fatigue, and consensus factors/rules have been developed and approved by the relevant Code committees since termination of the CRBRP project.

The previously referenced study by the Pressure Vessel Research Council ${ }^{2}$ identified weldments as a major issue that must be resolved to ensure long-term safety of reactor components.

Quoting from this study:

The ASME Code Subcommittee on Properties of Metals (SC-P) has established a joint Subgroup on Strength of Weldments with the Subcommittee on Welding (SC-IX) to review weldment properties at elevated temperature. Research and development in this area, which is also pursued by the U.S. governmentsponsored national laboratories, universities, and industry, addresses design analysis methods, design criteria, and other special requirements to improve the life predictions of welded structures. For example, weld reduction factors based upon experimental and analytical work are now included in the 1986 version of Code Case N47. A detailed metallurgical and inelastic structural evaluation of weld cracks, observed in a prototypic nozzle test, suggests that higher yield strength, but lower ductilities of the HAZ and the weld metal under triaxial loading are the principal contributors to the observed creep-rupture cracks at high 'primary' pressure loading. The differences in the weldment and base material properties may assume greater importance in a design where the predominant loadings are due to strain-controlled, thermal transient events, which cause yielding in both the base metal and the higher strength weld materials. Recent unpublished Japanese weldment test data suggest that the weld is 'weaker' (lower yield strength) than the base material. Consequently, in the Japanese scaled structural tests, the failure due to creep-fatigue inter-action occurred in the contiguous, 'stronger' base material and not in the welds. A simplified procedure ... was developed to evaluate creep-fatigue strength of weldments to account for the metallurgical and geometric discontinuities at welded joints. A combined experimental analytical evaluation of CRBRP multimetallic transition joints suggests that the structural integrity of 'cold' joints can be assured for a full 30-year plant life. However, the structural integrity of 'hot' joints can be assured for only about a 15-year plant life. Improved fabrication methods, design rules and criteria, and verification and validation of inelastic analysis methods for weldments are required to improve design methods, clarify design rules, and compensate for the lack of LMFBR operating experience. A number of development programs have been initiated, and some information should be collected, evaluated and supplemented (as, and if, necessary) to support the development of weldment design criteria. Specific recommendations are as follows:

1. Collect and assess weldment fatigue and long-term creep-fatigue material data, and evaluate the applicability of current analytical methods and criteria applied to weldments.

2. Conduct short-term (deformation) and long-term (failure) weldment characterization and structural tests to understand weldment behavior and to develop and verify simplified and detailed analysis methodology.

3. Develop methodology to predict creepcrack initiation in weldments and creepcrack growth behavior due to cyclic thermal and mechanical loadings and long hold-times at elevated temperature. 
4. Evaluate and quantify various weld effects (e.g., property mismatch, weld geometry, residual stresses, weld fabrication proced-ures, triaxiality, etc.) and recommend inclusion of significant weld characteristics in routine design analysis. $^{2}$

This issue is categorized as a "design bases safety issue."

\section{Issue 15: Lack of Flaw Assessment Procedures}

Under the rules of ASME CCN47, failure is defined as "crack initiation." Under the current Code design methodology, there are assumed to be no flaws or cracks in a newly constructed reactor component. Any flaws detected prior to start-up are repaired prior to full-power operation. There is general concern that repair of a flaw may introduce additional damage rather than reduce or eliminate damage. The best approach may be to identify the flaw, particularly for smaller flaws, and monitor the flaw during ISIs. It is generally agreed by the design and fabrication communities that there will be flaws in components of a new reactor system upon completion of construction. There is also the lingering question, what is a crack? At what point does an imperfection, microcrack of one to a few grain facets, etc. become a crack? In addition to the rules of CCN47, the ISI rules of ASME Code Sect. XI do not contain a crack growth methodology such that residual life can be estimated when ISI identifies cracks that are likely to be there after the reactor begins operation. Rules consistent with the high-temperature materials in $\mathrm{CCN} 47$ and also with inelastic (creep and plasticity) material behavior need to be developed and either incorporated into $\mathrm{CCN} 47$ and Sect. XI or into NRC regulatory guides. Overall needs include flaw modeling guidance and experimentally validated methods for predicting component failure under creep, creep-fatigue, and creep ratcheting conditions. The needed methodologies are particularly relevant to the development of leak-before-break arguments in critical LMR components.

Quoting from the previously referenced Pressure Vessel Research Council findings: ${ }^{2}$

Flaw tolerance assessments have been performed for a number of breeder reactor components and systems, the most noted example being the primary heat transport system piping in a loop-type reactor. These assessments have been performed on a case-bycase basis by direct application of fracture mechanics technology and the test data generated under the U.S. Department of Energy sponsored High-Temperature Structural Design (HTSD) program. While this approach has proven to be effective and flexible, the development of simpler, more general, engineering procedures for assessing the structural adequacy of flawed components would enhance the defensibility and reduce the cost of flaw tolerance evaluations....The recommendations for future research to verify flaw acceptance criteria, and methods for predicting fatigue and creep-crack growth in elevated temperature service, are as follows:

1. evaluation of crack growth in the creep regime including effects of creep-fatigue interaction,

2. influence of residual stresses in weldments on crack growth,

3. behavior of cracks in transition welds,

4. influence of thermal striping effects on fatigue and creep crack growth,

5. behavior of short cracks and cracks in multiaxial stress fields,

6. improvement of methods in inelastic fracture mechanics,

7. verification of analytical methods by smallscale component tests,

8. evaluation of structural integrity by probabilistic fracture mechanics methods. ${ }^{2}$

An Electric Power Research Institute (EPRI) sponsored effort to develop high-temperature flaw assessment procedures was recently completed at ORNL; however, these procedures have not been adopted for ASME Code use. ${ }^{28}$

This issue is categorized as a "design bases safety issue." 
Issue 16: Uncertainty of Multiaxial Stress State Effect

The effect of multiaxial stress state on failure of components at elevated temperatures is poorly understood. Current $\mathrm{CCN} 47$ rules are intended to provide conservative life predictions for creep-induced timedependent failure modes. Validation of the rules is typically based on laboratory uniaxial test data. There have been very few multiaxial laboratory or component experimental tests of sufficient duration $(>10 \%$ of design life) to adequately validate the accuracy of current rules, particularly with reference to an expected design life of 60 years.

This issue is categorized as a "design bases safety issue."

\section{Issue 17: Uncertainty of Nonradial (Nonpro- portional) Loading Effect}

Creep and creep-fatigue damage accumulation under complex multiaxial loadings is poorly understood by designers and material scientists. There is almost no laboratory or component data to validate $\mathrm{CCN} 47$ rules as relates to long-term ( $>10 \%$ of design life) nonradial loadings. Current $\mathrm{CCN} 47$ rules treat both creep and fatigue damage as scaler quantities, whereas data show damage accumulation to be tensorial (directional) in nature. If one loads a specimen or component to a constant effective stress level in the "Y" direction for half life, then unloads and reloads to the same effective stress level in the " $\mathrm{X}^{n}$ direction until failure (where " $\mathrm{X}$ " is normal to " $\mathrm{Y}^{n}$ ), then failure time is typically significantly different from the life of an analogous specimen loaded to the same effective stress level in either the " $\mathrm{X}^{n}$ or " $\mathrm{Y}^{n}$ direction and held there until failure. The few creep-rupture tests that have been conducted at ORNL under nonradial loadings tend to validate a conservative life prediction for the linear time-fraction damage methodology, thus indicating that treating damage as a scaler may result in conservative life predictions under creep-rupture and possibly under creep-fatigue loadings; however, there are very little data on which to base this assumption.

This issue is categorized as a "design bases safety issue."
Issue 18: Lack of Understanding/Validation of Notch Weakening Effects

Demonstrating adequate life at notchlike discontinuities poses the most difficult test of the hightemperature structural design methodology. Along with weldments, this was the major concern of the NRC during CRBRP licensing, and a 5-year confirmatory program was, therefore, specified by NRC. The effects of inelastic behavior and of uncertainties in long-term cyclic material properties on creep and fatigue damage at notches were key questions. A closely related question had to do with the use of average (vs maximum, minimum, or combinations thereof) properties for design. The combination of relatively large, unpredictable, material property variations, arising potentially from permissible variations in alloy composition, combined with inherent inaccuracy in the analytical process for predicting stresses and strains (constitutive equations, finite-element approximations, etc.) make accurate prediction difficult. Additional failure tests and analyses, particularly for bending loadings, are needed to demonstrate the adequacy of the Code methodology for notchlike geometries. Quoting Ref. 3 (NRC Finding No. 5),

The basic allowable stress limits of the Code are based on unnotched creep specimen test data. Stress raisers influence the creep behavior of the entire wall in two basic ways. They introduce a constraint against inelastic flow by inhibiting slip line development. This is manifested in a reduction in the average stress intensity in the net section (a notch strengthening effect). Stress raisers also introduce a site where creep-rupture damage could cause early crack initiation and more rapid crack propagation (a notch weakening effect). Although the combined effect is notch strengthening in most cases, an evaluation is needed to determine what geometric, loading, and material parameters could cause significant notch weakening, particularly for longterm loading at elevated temperatures. Loading conditions such as transverse shear do not introduce any notch strengthening and have contributed to weldment cracking at structural discontinuities.

In addition to a parametric study of this effect, selected laboratory tests should be conducted to 
validate the effect for a few selected relevant geometries as well as to validate the computational methods used in the parametric analyses.

To the knowledge of this project team, there are no known current programs of significance that have the needed resources and are focused (1) on this problem at the depth needed and (2) on developing the needed laboratory and component data for validation of design methods.

This issue is categorized as a "design bases safety issue."

\section{Issue 19: Lack of Conservatism in Code Rules for Simplified Fatigue Evaluations Based on Plastic Strain Concentration Factors}

This issue was Finding No. 7 in the CRBRP design certification process ${ }^{3}$ and continues to be an issue. Quoting Finding No. 7, "This issue concerns the use of the plastic strain concentration factors, $\mathrm{K}_{e}$, in performing fatigue evaluations. The simplified methods of the ASME Code, used by the Applicants (e.g., in the core support structure--support cone weld analysis), allow this factor to be unity until the primary plus secondary stress range exceeds $3 \mathrm{~S}_{\mathrm{m}}$. Actually, this factor begins to exceed unity when the local maximum stress range, including the elastic stress concentration factor, exceeds $2 \mathrm{~S}_{\mathrm{y}}$. Moreover, strain multipliers for the concentration of plastic strain on the weaker side of a product form or materials interface are not included in existing formula for $\mathrm{K}_{e}$ in the Code. The lack of conservatism in the simplified elastic-plastic method of the ASME Code has been pointed out in the published literature.

This issue is categorized as a "design bases safety issue."

Issue 20: Lack of Validated Rules/Guidelines to Account for Seismic Effects at ElevatedTemperature

This issue was "Finding No. $2^{n}$ in the CRBRP design certification process ${ }^{3}$ and continues to be an issue. Quoting from Finding No. 2,

ASME Code Case 1592 (i.e., CCN47) imposes limits on various inelastic strains accumulated within the life of a component. The life history is described by grouped cycles of limited intensities. The consequence of varying the loading sequence is not important below the creep regime, and stresses are classified into stress-controlled primary and strain-controlled secondary values. These stress values are then used to perform structural analyses of the cyclic life of the structure. Seismic events impose high shortterm primary stresses on the structure. The seismic loads affect the inelastic strain accumulation by changing the residual stresses that produce enhanced creep. Seismic loads also produce plastic strain accumulation generated within each motion if the intensity of the shake is great enough to cause plastic ratcheting. The relaxation of high residual stresses that exist after a seismic event produces enhanced creep during subsequent operation at elevated temperatures. Consequently, the sequence of loading becomes important in the creep regime.

In the CRBRP case, the issue was 'resolved' by NRC requiring Westinghouse to take into account any enhanced creep (ratcheting) and any creep-rupture damage resulting from residual stresses at local stress raisers following seismic events. It necessarily in-cluded consideration of the sequence of the seismic events with respect to the operating transients. The ASME Code does not provide rules or guidance on how to idealize the cyclic loading histories to ensure a conservative result. In addition "since an inelastic dynamic analysis of LMFBR structural components is at least an order of magnitude more expensive than a static inelastic analysis, a rigorous definition of a conservative worst-case loading order is not practical."

This issue is categorized as a "design bases safety issue."

\section{Issue 21: Lack of Inelastic Design Procedures for Piping}

This issue was previously identified and summarized in some detail in Ref. 2. Selected excerpts from this reference are summarized in the following four paragraphs to identify and bring out the issue. Quoting Ref. 2: 
elastic follow-up is not clearly defined in the ASME Code. The term 'elastic follow-up' was coined by Robinson to explain possible creep strain concentration in piping systems due to strain-controlled thermal expansion loading. The elastic follow-up concept is used in the 'elastic' design rules to include inelastic (plastic and creep) effects. Elastic follow-up is not a failure mode. In fact, an inelastic analysis is performed to predict the stress and strain redistributions within a pressure vessel or piping structure. In the absence of a clear and concise Code definition of elastic follow-up, there are as many definitions as there are experts in the field. Since elastic follow-up is not clearly and unambiguously defined in the Code, it is easy to challenge the design of a complex structure on the basis that elastic follow-up was not considered in the analysis.

Confusion has persisted in this area because elastic follow-up is simplistically, and sometimes improperly, used to describe plastic and strain concentrations in structural components. The confusion is more a mater of definition than of structural behavior. Detailed inelastic analysis of a typical, CRBRP, primary heat transport piping system has clearly shown that elastic follow-up is not significant in welldesigned piping systems. A simplified elastic analysis procedure, verified by a detailed inelastic analysis, has been developed to obtain a numerical estimate of elastic follow-up, and thus satisfy U.S. NRC concerns regarding the long-term structural integrity of CRBRP piping systems. Other simplified methods to estimate elastic follow-up have been developed in Europe and Japan. These simplified procedures can be used to estimate elastic follow-up in any piping system configuration. For example, scaled piping loop tests on the MONJU plant in Japan have not revealed any significant elastic follow-up in well designed piping systems. Informal discussions with practicing engineers also indicate that, in prototype plants, they have not found a piping configuration where elastic follow-up is significant, or a failure in plant operation which can be directly attributed to elastic follow-up.
The phenomenon of elastic follow-up should be more clearly defined in the ASME Code, and a procedure, such as one of those proposed in references..., should be provided to the designer to evaluate elastic follow-up in LMFBR piping systems. Additionally, references to vague terms such as 'secondary stresses with a large amount of elastic followup...' should be clarified, if not removed, from the ASME Code. ${ }^{2}$

It should be noted that since termination of the CRBRP Project, ASME has modified $\mathrm{CCN} 47$ rules to classify all secondary stresses with elastic follow-up as a primary stress that cleared up some of the Code vagueness identified in the Pressure Vessel Research Council study (see CCN47, Section T-1331 d).

From an ORNL perspective, the primary need here is to reach a consensus agreement on a standardized method of analysis and the associated definitions, to carefully document that method, and then to incorporate the standardized method in the ASME Code or into NRC regulatory guides. Although there is a need to expand the stress indices for piping components and to experimentally validate their extension to use for time-dependent failure modes at elevated temperatures, the foremost technological need is for an experimentally validated procedure for assessing elastic follow-up, which is the potential for a pipe line to act as a spring and to continue to load after a dynamic event is completed and cause inelastic strain accumulation in weaker regions of the pipe line.

This issue is categorized as a "design bases safety issue."

\section{Issue 22: Overly Conservative Buckling Rules}

This issue focuses on excess conservatism in the CCN47 buckling rules. The issue was identified previously by the Pressure Vessel Research Council. ${ }^{2}$ Quoting from their study:

The buckling charts presented in Sections I, III and VIII of the ASME Boiler and Pressure Vessel Code were developed for cylindrical shells and spherical shells subjected to external pressure, and for cylindrical shells subjected to axial compression. To accommodate geometries and loads not covered by Section III design charts, such as piping elbows, and to 
utilize recent advances in numerical analysis methods, buckling limits are imposed in Code Case N-47 in the form of buckling factors which limit the design load relative to the buckling or collapse load.

Experience with the application of buckling rules to CRBRP piping systems and pressure vessels suggests that a buckling load factor of three is very conservative for pipes, elbows, and pressure vessels which buckle in the plastic range. The rationale for reducing the load factor is that the buckling load in the plastic range is initially imperfection-insen-sitive and that plastic collapse occurs gradually, after significant plastic deformation. When elevated-temperature buckling experiments were performed on elbows, the results suggested that the plastic buckling load measured in as-fabricated elbows is about $50 \%$ higher than that predicted by using the minimum material properties given in Code Case N-47; also, the experimentally observed creep buckling time is about ten times that predicted by analysis.

Code Case $\mathrm{N}-47$ specifies lower design factors for strain-controlled buckling than for loadcontrolled buckling. However, to guard against buckling in an interactive mode, the Code conservatively specifies that the higher design factors applicable to load-controlled buckling be used for thermally induced (straincontrolled) loads, when a combination of strain- and load-controlled loading is imposed on the structure. This requirement increases the restrictions already imposed by the very conservative design factors.

There is a need to remove ambiguous treatment of strain- and load-controlled buckling in current design procedures and to reduce design factors, when detailed nonlinear analysis procedures are used, to predict collapse of LMFBR structures.
This issue is categorized as a "design bases economic issue."

\section{Issue 23: Need for Thermal Stratification Design Guidelines}

Thermal stratification (thermal gradient within the coolant across a pipe diameter as well as along the pipe length) within piping has been shown to occur when there is piping connecting two fluid reservoirs at different temperatures and when flow rate is essentially zero. Thermal stratification can lead to different axial expansions across a pipe diameter and thus to significant axial bending stresses. This condition can occur, for example, in pressurized water reactor (PWR) pressurizer piping, and also in residual heat removal (RHR) system piping attached to the reactor hot leg piping. Depending on the specific designs of advanced high-temperature reactor plants, such as LMR plants, there may also be components and/or interconnected components that may experience significant levels of thermal stratification that must be accommodated in the design process.

In older reactor designs, the designers did not account for the thermal stresses and potential thermal shock effects due to thermal stratification; however today's designers appear to be very much aware of this phenomenon, as evidenced by the several papers presented on this subject at the June 1992 ASME Pressure Vessel and Piping Meeting held in New Orleans. They would, therefore, be expected to and in all likelihood they will account for these effects in future reactor plant designs. NRC has issued information bulletins alerting the reactor manufacturer and utility community to this problem. ${ }^{29-31}$ Design methods are available to deal with this problem. This apparent issue is, therefore, considered to be resolved and is not addressed further in this report.

This issue is categorized as a "design bases safety issue." 


\section{Issue Characterization}

To assist NRC in establishing priorities and in taking actions that they deem necessary relative to resolution of the issues identified here, a means for characterizing the issues was developed. Issues were characterized by (A) Issue "Type;" (B) Issue "Bases;" and $(C)$ Issue "Level" in accordance with the definitions summarized below.

\section{A. Issue Type}

(S) safety

(E) economic

B. Issue Bases

"material and data base"

"design bases"

both

C. Issue Levels

1. An issue that, if not resolved, will result in Code rules that are not sufficient for design of reactor components for a 60 -year life is designated as a Level 1 Issue.

2. An issue arising from Code rules that currently exist and are known to be inadequate (inaccurate) but can be used for component design and, therefore, could result in nonconservative (unsafe) component designs and potentially catastrophic failures is designated as a Level 2 Issue.
3. An issue arising from Code rules that currently exist and, therefore, can be used for design, but (a) lack sufficient validation in the opinion of the authors, and, therefore, leave serious doubt as to reactor safety over the expected life cycle; and (b) are expected to require a relatively long period of time to resolve is designated as a Level 3 Issue.

4. An issue arising from Code rules that currently exist and, therefore, can be used for design, but (a) lack sufficient validation in the opinion of the authors, and, therefore, leave serious doubt as to reactor safety over the expected life cycle; and (b) is expected to require relatively large allocation of resources to resolve is designated as a Level 4 Issue.

5. An issue where there are no specific Code rules or regulatory guides, but in the opinion of the authors, design rules or guidance is needed to ensure either the safe design and operation of reactor plants or to provide for cost-effective designs is designated as a Level 5 Issue.

6. An issue arising from Code rules that exist and can be used for design, but needing additional data, validation, etc. and, with the needed information, the issue can be cleared up without excessive funding or without a long programmatic effort is designated as a Level 6 Issue.

Based on the criteria established, the issues were partitioned and are summarized in Table 2. 
Table 2. Summary of issues

\begin{tabular}{|c|c|c|c|}
\hline $\begin{array}{l}\text { Issue } \\
\text { No. }\end{array}$ & $\begin{array}{l}\text { Issue } \\
\text { lever }\end{array}$ & Issue & $\begin{array}{c}\text { Category } \\
\text { (type-bases) }\end{array}$ \\
\hline 1 & 1 & $\begin{array}{l}\text { Lack of material property allowable } \\
\text { design data/curves for a } 60 \text {-year } \\
\text { design life }\end{array}$ & M-S \\
\hline 6 & 2,6 & Degradation effect of small cyclic stresses & M-S \\
\hline 16 & 2 & Uncertainty of multiaxial stress state effects & D-S \\
\hline 19 & 2 & $\begin{array}{l}\text { Lack of conservatism in Code rules for simplified } \\
\text { fatigue evaluations based on plastic strain } \\
\text { concentration factors }\end{array}$ & D-S \\
\hline 18 & 2 & $\begin{array}{l}\text { Lack of understanding/validation of notch } \\
\text { weakening effects }\end{array}$ & D-S \\
\hline 14 & $3,4,5$ & $\begin{array}{l}\text { Lack of a validated weldment } \\
\text { design methodology }\end{array}$ & D-S \\
\hline 20 & 3,4 & $\begin{array}{l}\text { Lack of validated rules/guidelines to account for } \\
\text { seismic effects at elevated temperature }\end{array}$ & D-S \\
\hline 2 & 3,4 & $\begin{array}{l}\text { Degradation of material properties } \\
\text { at high temperatures due to long-term } \\
\text { irradiation }\end{array}$ & M-S \\
\hline 3 & 3,4 & $\begin{array}{l}\text { Degradation of material properties } \\
\text { due to long-term thermal aging }\end{array}$ & M-S \\
\hline 4 & 3,4 & $\begin{array}{l}\text { Degradation of material properties due } \\
\text { corrosion phenomena }\end{array}$ & M-S \\
\hline 12 & 3 & Lack of reliable creep-fatigue design rules & M\&D-S \\
\hline 11 & 4 & $\begin{array}{l}\text { Lack of validated thermal striping materials } \\
\text { and design methodology }\end{array}$ & M\&D-S \\
\hline 7 & 5 & $\begin{array}{l}\text { Creep-induced failures at temperatures } \\
\text { below CCN47 limits }\end{array}$ & M-S \\
\hline 9 & 5 & $\begin{array}{l}\text { Lack of a design methodology for modified } \\
9 \mathrm{Cr}-1 \text { Mo steel }\end{array}$ & $M \& D-E$ \\
\hline 10 & 5 & $\begin{array}{l}\text { Lack of understanding/validation of effects } \\
\text { of short-term overload events on subsequent } \\
\text { mechanical properties }\end{array}$ & M\&D-S \\
\hline
\end{tabular}


Table 2 Summary of issues (continued)

\begin{tabular}{|c|c|c|c|}
\hline $\begin{array}{l}\text { Issue } \\
\text { No. }\end{array}$ & $\begin{array}{l}\text { Issue } \\
\text { lever }\end{array}$ & Issue & $\begin{array}{c}\text { Category } \\
\text { (type-bases) }\end{array}$ \\
\hline 15 & 5 & Lack of flaw assessment procedures/rules & D-S \\
\hline 21 & 5 & Lack of inelastic design procedures for piping & D-S \\
\hline 5 & 6 & $\begin{array}{l}\text { Lack of property allowables based on } \\
\text { current melting practices }\end{array}$ & M-S \\
\hline 8 & 6 & $\begin{array}{l}\text { Use of average vs minimum material } \\
\text { properties in design }\end{array}$ & M\&D-S \\
\hline 13 & 6 & Difficult, overly-conservative ratcheting rules & D-E \\
\hline 17 & 6 & $\begin{array}{l}\text { Uncertainty of nonradial (nonproportional) } \\
\text { loading effects }\end{array}$ & D-S \\
\hline 22 & 6 & Overly conservative buckling rules & D-S \\
\hline
\end{tabular}

\section{${ }^{a}$ Issue Levels}

$1=$ Code rules must be modified

2 = Inaccurate, potentially nonconservative Code rules

3 = Additional validation needed; extensive time may be required

$4=$ Additional validation needed; extensive resources may be required

$5=$ Code rules or regulatory guides are needed but do not exist

$6=$ Additional validation needed; time/resource needs are not extensive

${ }^{b}$ Issue Type and Bases Catagories

$M=$ material and data base issue

$\mathrm{D}=$ design bases issue

$M \& D=$ both $M$ and $D$ issue

$-S=$ safety issue (public placed at risk)

$-\mathrm{E}=$ economic issue (increases plant cost) 


\section{Plans For Resolution of the Issues}

Each of the issues identified in this study was reviewed to develop, in a scoping sense, plans for resolving the issue. It was not possible to address each issue in the depth needed to develop detailed plans. However, in each case, descriptive subtasks were developed. Each plan focuses on resolving the technical issue and then developing recommended rules for incorporation into the ASME Code (denoted as Code Package) or into NRC regulatory guidelines. This section summarizes the scoping plans developed for each of the issues. More detailed plans, including estimated cost and time schedules could be developed if requested by NRC. Issues and plan recommendations are summarized in Table 3. 
Table 3. Summary of plans for resolving identified issues

$\begin{array}{ccc}\text { Issue } & \begin{array}{c}\text { Brief task } \\ \text { description }\end{array} & \text { Program recommendations } \\ \text { No. } & \end{array}$

1

2

3

4

5

6

7

8
Lack of material property allowable design data/curves for a 60 -year design life

Degradation of material properties at high temperature due to long-term irradiation

Degradation of material properties due to long-term thermal aging

Degradation of material properties due to corrosion phenomena

Lack of property allowables based on current melting practices

Degradation effect of small cyclic stresses

Creep-induced failures at temperatures below CCN47 limits

Use of average vs minimum material properties in design
A. Review/assess/identify data needs
B. Confirmatory laboratory testing
C. Code package development

A. Problem review and assessment

B. Data collection/test matrix definition

C. Model development

D. Confirmatory hot cell testing

E. Code rule/regulatory guide package development
A. Problem/experience review and assessment
B. Data collection/test matrix definition
C. Assess planned Code knock-down factors
D. Confirmatory laboratory testing (if required)
E. Code rule/regulatory guide package development
A. Problem/experience review and assessment
B. Data collection/test matrix definition
C. Model development
D. Confirmatory laboratory testing
E. Code rule/regulatory guide package development
A. Problem review and assessment
B. Data collection/correlation
C. Selected laboratory validation testing
D. Code recommendations
A. Problem review and assessment
B. Confirmatory laboratory testing
C. Code/regulatory guide recommendations
A. Problem/experience review and assessment
B. Confirmatory laboratory testing
C. Code/regulatory guide recommendations
A. Problem/experience review and assessment
B. Probabilistic parametric studies
C. Structural test correlation/validation
D. Code/regulatory guide recommendations 
Table 3. Summary of plans for resolving identified issues (continued)

\begin{tabular}{lll}
\hline $\begin{array}{c}\text { Issue } \\
\text { No. }\end{array}$ & $\begin{array}{c}\text { Brief task } \\
\text { description }\end{array}$ & Program recommendations \\
\hline
\end{tabular}

9

Lack of a design methodology for modified 9 Cr-1 Mo

10

11

12

13
Lack of understanding/validation of effects of short-term overload events on subsequent mechanical properties

Lack of validated thermal striping materials and design methodology

Lack of reliable creep-fatigue design rules

Difficult, overlyconservative ratcheting design rules

Lack of a validated weldment design methodology

Lack of flaw assessment procedures/ rules for high temperatures
A. Characterization of $9 \mathrm{Cr}-1$ Mo behavior

B. Design methodology development
a. Constitutive equations
b. Failure criteria
c. Simplified methods

C. Code rule/regulatory guide development
A. Problem review and assessment
B. Confirmatory laboratory testing
C. Code rule/regulatory guide recommendations
A. Problem review and assessment
B. Characterize range of striping conditions
C. Develop high-temperature crack growth methodology
D. Confirmatory structural testing
E. Establish material allowables
F. Code rule/regulatory guide package development
A. Problem review and assessment
B. Creep-fatigue model development
C. Confirmatory uniaxial laboratory testing
D. Confirmatory multiaxial testing
E. Code rule/regulatory guide package development
A. Problem review and assessment
B. Ratcheting model/rules development/simplification
C. Confirmatory analyses
D. Code Rule/regulatory guide package development
A. Problem review and assessment
B. Weldment flaw characterization
C. Design methodology development
D. Confirmatory structural testing (particularly under thermal transient conditions)
E. Code rule/regulatory guide package development
A. Problem review and assessment
B. Flaw characterization study
C. Crack growth and design methodology development
D. Confirmatory laboratory testing
E. Confirmatory structural testing
F. Code rule/regulatory guide package development 
Plans

Table 3. Summary of plans for resolving identified issues (continued)

Issue

Brief task

No.

description

Program recommendations

16

17

18

19

20

21

22
Uncertainty of multi-

axial stress state

effects

Uncertainty of non-

radial (non-

proportional)

loading effects

Lack of understand-

ing/validation of

notch weakening

effects

Lack of conservatism

in Code rules for

simplified fatigue

evaluations based on

plastic strain

concentration factors

Lack of validated

rules/guidelines to

account for seismic

effects at elevated

temperature

Lack of inelastic

design procedures

for piping

Overly

conservative

buckling rules
A. Problem review and assessment

B. Confirmatory multiaxial testing

a. Creep-rupture

b. Creep-fatigue

c. Code rule/regulatory guide recommendations

A. Problem review and assessment

B. Confirmatory non-radial laboratory testing

a. Creep-rupture

b. Creep-fatigue

C. Code rule/regulatory guide recommendations

A. Problem review and assessment

B. Parametric study of geometric notches, loading conditions and material properties

C. Confirmatory structural testing

D. Code rule/regulatory guide package development
A. Problem review and assessment
B. Data/rule correlations
C. Simplified rule development
D. Code rule/regulatory guide package development

A. Problem review and assessment

B. Cycle counting/histogram ordering simplified model Development

C. Confirmatory testing (or data/model correlation if data exist)

D. Code rule/regulatory guide package development
A. Problem review and assessment
B. Analysis methodology/procedure development
C. Analysis/experience correlations
D. Code rule/regulatory guide package development
A. Problem review and assessment
B. Buckling data compilation
C. Analysis methodology/rule development
D. Code rule/regulatory guide package development 


\section{Summary of the Major Issues}

Identification of the major issues tends to be a subjective process; however, after a review of the overall list of issues, ten were identified as the major issues. If unresolved, in the opinion of the authors, these issues would (1) place the public at the greatest risk or (2) result in the existing ASME CCN47 not having sufficient design allowables, curves, rules, etc., for design of the advanced high-temperature reactor plants for an 60-year operating life. Those issues which have been designated as the ten major ones are summarized in Table 4. 
Table 4 Summary of the ten major issues

\begin{tabular}{|c|c|c|c|}
\hline $\begin{array}{l}\text { Issue } \\
\text { No. }\end{array}$ & $\begin{array}{l}\text { Issue } \\
\text { Lever }\end{array}$ & Issue & $\begin{array}{l}\text { Category } \\
\text { (type-bases) }^{b}\end{array}$ \\
\hline 1 & 1 & $\begin{array}{l}\text { Lack of material property allowable design } \\
\text { data/curves for A } 60 \text {-Year design life }\end{array}$ & M-S \\
\hline 18 & 2 & $\begin{array}{l}\text { Lack of understanding/validation of notch } \\
\text { weakening effects }\end{array}$ & D-S \\
\hline 14 & $3,4,5$ & Lack of a validated weldment design methodology & D-S \\
\hline 2 & 3,4 & $\begin{array}{l}\text { Degradation of material properties at high } \\
\text { temperatures due to long-term irradiation }\end{array}$ & M-S \\
\hline 3 & 3,4 & $\begin{array}{l}\text { Degradation of material properties due to } \\
\text { long-term corrosion phenomena }\end{array}$ & M-S \\
\hline 11 & 4 & $\begin{array}{l}\text { Lack of validated thermal striping materials } \\
\text { and design methodology }\end{array}$ & M\&D-S \\
\hline 12 & 3 & Lack of reliable creep-fatigue design rules & M\&D-S \\
\hline 15 & 5 & Lack of flaw assessment procedures & D-S \\
\hline 21 & 5 & Lack of inelastic design procedures for piping & D-S \\
\hline 20 & 3,4 & $\begin{array}{l}\text { Lack of rules/guidelines to account for seismic } \\
\text { effects at elevated temperature }\end{array}$ & D-S \\
\hline
\end{tabular}

\section{${ }^{a}$ Issue Levels}

$1=$ Code rules must be modified

2 = Inaccurate, potentially nonconservative code rules

3 = Additional validation needed; extensive time may be required

$4=$ Additional validation needed; extensive resources may be required

$5=$ Code rules or regulatory guides are needed but do not exist

6 = Additional validation needed; time/resource needs are not extensive

\section{${ }^{b}$ Issue type and bases categories}

$\mathrm{M}=$ material and data base issue

$\mathrm{D}=$ design bases issue

$M \& D=$ both $M$ and $D$ issue

$-S=$ safety issue (public placed at risk)

$-E=$ economic issue (increases plant cost) 


\section{References}

1. "Code Case N47-29, Class I Components in Elevated Temperature Service, Section III, Division 1," Cases of ASME Boiler and Pressure Vessel Code, American Society of Mechanical Engineers, New York, December 1990.

2. A. K. Dhalla, ed., "Recommended Practices in Elevated Temperature Design: A Compendium of Breeder Reactor Experiences (19701987), Volume 1, Current Status and Future Directions," Bulletin 362, Welding Research Council, New York, April 1991. ${ }^{\dagger}$

3. U.S. Nuclear Regulatory Commission, Safety Evaluation Report Related to the Construction of Clinch River Breeder Reactor Plant, USNRC Report NUREG-0968, Vol. 1, Main Report, U.S. Nuclear Regulatory Commission, March 1983.

4. M. L. Grossbeck, K. Ehrlich, and C. Wassilew, "An Assessment of Tensile, Irradiation Creep, Creep Rupture, and Fatigue Behavior in Austenitic Stainless Steels with Emphasis on Spectral Effects," J. Nucl. Mater. 174, 264, $(1990) .^{\dagger}$

5. M. L. Grossbeck and E. E. Bloom, "In-reactor Uniaxial Fracture Strain of 20-Cold-Worked Type 316 Stainless Steel," p. 53 in Conf. on Creep in Stainless Steels December 5, 1977, London, England, British Nuclear Energy Society, London, 1977.

6. B. van der Shaaf, M. I. de Vries, and J. D. Elen, "Influence of Irradiation on Creep and Creep-Fatigue Interaction of Type 304 Stainless Steel," Conf. on creep in Stainless Steels held December 5, 1977, London, England, British Nuclear Energy Society, London, 1977.

7. B. Van Der Schaaf, M. I. De Vries, and J. D. Elen, "The effect of Irradiation on Creep, Fatigue and their interaction of DIN 1.4948 (Type 304) Stainless Steel Plate and Welded

\footnotetext{
Available from American National Standards Institute, 1430 Broadway, New York, NY 10018, Copyrighted.

${ }^{\dagger}$ Available in public technical libraries.
}

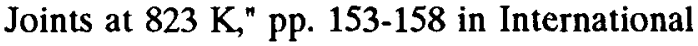
Conference on Engineering Aspects of Creep (Volume I), September 15-19, 1980, Conference Publication 1980-5, Institution of Mechanical Engineers, London, 1980.

8. M. L. Grossbeck and K. C. Liu, Fatigue Behavior at $650^{\circ} \mathrm{C}$ of $20 \%$ Cold-Worked Type 316 Stainless Steel Irradiated at $550^{\circ} \mathrm{C}$ in the High-Flux Isotope Reactor (HFIR), ASTM STP 870 (1985), ASTM, Philadelphia, p. $732 .^{+}$

9. M. L. Grossbeck, "Empirical Relations for Tensile Properties of Austenitic Stainless Steels Irradiated in Mixed-Spectrum Reactors," J. Nucl. Mater., 179-181, 568 (1991) ${ }^{\dagger}$

10. "Properties of Stainless Steel," MPC-Vol. 26, PVP-Vol. 132, ed. M. Prager, ASME, New York (1987). ${ }^{\dagger}$

11. C. R. Brinkman et al., Oak Ridge National Laboratory, The Development of StressRupture Reduction Factors for Weldments and the Influence of Pretest Thermal Aging to 50,000 h on the Stress-Rupture and Microstructural Properties of Modified 9 Cr-1 Mo Steel, ORNL/TM-11459, March 1990:

12. R. W. Neu and H. Sehitoglu, "ThermalMechanical Fatigue, Oxidation, and Creep," Metallurgical Transactions 20A, 1755-1783 (1989). ${ }^{\dagger}$

13. "Code Case N-499, Use of SA-533 Grade B Class 1 Plate and SA-508 Class 3 Forgings and Their Weldments for Limited Elevated Temperature Service, Section III, Division 1," Cases of ASME Boiler and Pressure Vessel Code," American Society of Mechanical Engineers, New York, December 1990.

\footnotetext{
Available from American National Standards Institute, 1430 Broadway, New York, NY 10018, Copyrighted.

${ }^{\dagger}$ Available in public technical libraries.

*Available for purchase from National Technical Information Service, Springfield, VA 22161.
} 
14. Y. Asada et al., "Current Status of the Development of Advanced 316-Steel for FBR Structures," pp. 61-66 in Stress Classification, Robust Methods, and Elevated Temperature Design, PVP-Vol. 230, American Society of Mechanical Engineers, New York, $1992 .^{\dagger}$

15. F. Brohl et al., "Behavior of the $9 \%$ Chromium Steel P-91 in Short and Long Term Tests," Mannesmann Forschungsinstitut, Dulsburg, Germany, 1989.

16. H. P. Offer, J. F. Copeland, J. L. Yuen, and W. D. Challenger, "The Effects of Remelting and Heat Treatment on 2 1/4 Cr-1 Mo Steel Elevated Temperature Tensile Properties," pp. 195-200 in Effects of Melting and Processing Variables on the Mechanical Properties of Steel, MPC-6, American Society of Mechanical Engineers, New York, $1977 .^{\dagger}$

17. R. W. Swindeman, K. Farrell, and J. B. Conway, "Time-Dependent Fatigue of Type 304 Stainless Steel Containing Microvoids in the Starting Microstructure," pp. 121-137 in Thermal and Environmental Effects in Fatigue: Research-Design Interface, PVP-Vol. 71, American Society of Mechanical Engineers, New York, $1983 .^{\dagger}$

18. R. W. Swindeman, "Response of Ferritic Steels to Nonsteady Loading at Elevated Temperatures," pp. 31-42 in Research on Chrome-Moly Steels, MPC-21, American Society of Mechanical Engineers, New York, $1984 .^{\dagger}$

19. Guidelines and Procedures for Design of Class 1 Elevated Temperature Nuclear System Components, Nuclear Standard NE F 9-5T, U.S. DOE Office of Scientific and Technical Information, Oak Ridge, Tennessee, September 1986.

20. "Code Case N-253, Construction of Class 2 or Class 3 Components for Elevated Temperature Service, Section III, Division 1," Cases of ASME Boiler and Pressure Vessel Code,"

${ }^{\dagger}$ Available in public technical libraries.
American Society of Mechanical Engineers, New York, August 1990.

21. S. R. Patterson, "An Engineering Evaluation of Service Degraded 316N Main Steam Line Piping Weldments," Proceedings of 5th International Conference on Creep of Materials, ASM International, Materials Park, Ohio, 1992.

22. M. R. Patel, "Reactor Structural Evaluation," ALMR Advanced Liquid Metal Reactor (ALMR) Structural Materials Presentations to the Advisory Committee on Reactor Safeguards, held at San Francisco, California on May 21, 1992.

23. D. S. Griffin, et al., "Validation of Inelastic Analysis by Full Scale Component Testing," ASME Journal of Pressure Vessel Technology, Vol. 109, American Society of Mechanical Engineers, New York, pp. $42-49$ (Feb. 1987)..$^{+}$

24. W. Veljovich, Design Guidelines for Prevention of Thermal Striping Induced Failures of 304 and 316 SS, RI/RD90-224, Rockwell International, Rocketdyne Division, December 1990.

25. J. F. Delong et al., "Failure Investigation of Eddystone Main Steam Piping," Welding Journal 64, (10), 271-s through 280-s (October 1985). ${ }^{\dagger}$

26. S. Majumdar "Relationship of Creep, CreepFatigue, and Cavitation Damage in Type 304 Austenitic Stainless Steels", J. of Engr. Mat'ls 111, 123-131 (April 1989). ${ }^{\dagger}$

27. J. M. Corum "Evaluation of Weldment Creep and Fatigue Strength-Reduction Factors for Elevated-Temperature Design," J. of Pressure Vessel Technology, 112, 333-339 (1992). ${ }^{\dagger}$

\footnotetext{
Available from American National Standards Institute, 1430 Broadway, New York, NY 10018, Copyrighted.

tAvailable in public technical libraries.
} 
28. R. A. Ainsworth, M. B. Ruggles, and Y. Takahashi, Oak Ridge National Laboratory, Flaw Assessment Guide for HighTemperture Reactor Components Subject to Creep-Fatigue Loading, ORNL-6641, October $1990 .^{\ddagger}$

29. U.S. Nuclear Regulatory Commission, "Safety Injection Pipe Failure," U.S. NRC Information Notice No. 88-01, U.S. Nuclear Regulatory Commission, Washington, D.C., January 27, 1988.

${ }^{\ddagger}$ Available for purchase from National Technical Information Service, Springfield, VA 22161.
30. U.S. Nuclear Regulatory Commission, "Thermal Stresses in Piping Connected to Reactor Coolant Systems," U.S. NRC Bulletin No. 88-08, Supplements 1, 2, and 3, U.S. Nuclear Regulatory Commission, Washington, D.C., June 22, 1988; June 24, 1988; August 4, 1988; and April 11, 1989.

31. U.S. Nuclear Regulatory Commission, "Thermal Stratification in Feedwater System Piping," U.S. NRC Information Notice 91-38, U.S. Nuclear Regulatory Commission, Washington, D.C., June 13, 1989. 
NUREG/CR-5955

ORNL/TM-12266

Dist. Category R-1,R-2,R-5,R-7,R-8

\section{INTERNAL DISTRIBUTION}

1. J. J. Blass

2. M. H. Fontana

3. C. R. Brinkman

4. J. M. Corum

5. C. E. Pugh

6-15. R. L. Huddleston

16. W. J. McAfee

17. D. G. O'Connor
18. G. Slaughter

19-23. R. W. Swindeman

24. ORNL Patent Section

25. Central Research Library

26. Document Reference Section

27-28. Laboratory Records

29. Laboratory Records (RC)

\section{EXTERNAL DISTRIBUTION}

30. D.R. Diercks, Argonne National Laboratory, 9700 S. Cass Avenue, Argonne, IL 60439

31. J.A. Obrien, NRC-RES Division of Engineering, U.S. Nuclear Regulatory Commission, MS NL/S-217, Washington, DC 20555

32. Z.R. Rosztoczy, NRC-RES, Division of Engineering, U.S. Nuclear Regulatory Commission, MS NL/S-169, Washington, DC 20555

33-44. A. Taboada, NRC-RES, Division of Engineering, U.S. Nuclear Regulatory Commission, MS NL/S-217C, Washington, DC 20555

45. Office of Assistant Manager for Energy Research and Development, DOE-OR, Oak Ridge, TN 37831

46-55. Office of Scientific and Technical Information, P.O. Box 62, Oak Ridge, TN 37831 